\title{
A validated spectrofluorimetric method for the determination of nifuroxazide through coumarin formation using experimental design
}

\author{
Asmaa Ahmed El-Zaher and Marianne Alphonse Mahrouse*
}

\begin{abstract}
Background: Nifuroxazide (NF) is an oral nitrofuran antibiotic, having a wide range of bactericidal activity against gram positive and gram negative enteropathogenic organisms. It is formulated either in single form, as intestinal antiseptic or in combination with drotaverine (DV) for the treatment of gastroenteritis accompanied with gastrointestinal spasm. Spectrofluorimetry is a convenient and sensitive technique for pharmaceutical quality control. The new proposed spectrofluorimetric method allows its determination either in single form or in binary mixture with DV. Furthermore, experimental conditions were optimized using the new approach: Experimental design, which has many advantages over the old one, one variable at a time (OVAT approach).

Results: A novel and sensitive spectrofluorimetric method was designed and validated for the determination of NF in pharmaceutical formulation. The method was based upon the formation of a highly fluorescent coumarin compound by the reaction between NF and ethylacetoacetate (EAA) using sulfuric acid as catalyst. The fluorescence was measured at $390 \mathrm{~nm}$ upon excitation at $340 \mathrm{~nm}$. Experimental design was used to optimize experimental conditions. Volumes of EAA and sulfuric acid, temperature and heating time were considered the critical factors to be studied in order to establish an optimum fluorescence. Each two factors were co-tried at three levels. Regression analysis revealed good correlation between fluorescence intensity and concentration over the range 20-400 $\mathrm{ng} \mathrm{m}^{-1}$. The suggested method was successfully applied for the determination of NF in pure and capsule forms. The procedure was validated in terms of linearity, accuracy, precision, limit of detection and limit of quantification. The selectivity of the method was investigated by analysis of NF in presence of the co-mixed drug DV where no interference was observed. The reaction pathway was suggested and the structure of the fluorescent product was proposed. Statistical comparison between the presented method and a reported spectrophotometric one was carried out on pure and pharmaceutical formulation and revealed no significant difference.
\end{abstract}

Conclusion: The proposed method was considered economic, accurate, precise and highly sensitive. It could be easily applied in laboratory quality control for the analysis of $N F$ in pure form and in pharmaceutical dosage form.

Keywords: Nifuroxazide, Spectrofluorimetry, Experimental design, Coumarin, Ethylacetoacetate

\section{Background}

Nifuroxazide (NF, Scheme 1a), chemically designated as 4-hydroxy-N'-[(5-nitrofuran-2-yl) methylidene] benzohydrazide [1], is a nitrofuran derivative with wide range of bactericidal activity against gram positive and gram negative enteropathogenic organisms. It is poorly absorbed from the gastrointestinal tract and is extensively used as an

\footnotetext{
* Correspondence: mariannealphonse@yahoo.com

Pharmaceutical Chemistry Department, Faculty of Pharmacy, Cairo University, Kasr El-Aini St, Cairo 11562, Egypt
}

intestinal antiseptic in the treatment of colitis, acute and chronic diarrhea and gastroenteritis [2]. NF is an official drug in the British Pharmacopoeia [3] which recommends a potentiometric titration for its determination in pharmaceutical formulation. Various analytical techniques were reported for the analysis of $N F$ including colorimetry [4,5], spectrophotometry [5-8], near IR [9], TLC [10] and HPLC $[5,11]$. Electrochemical methods, such as polarography $[6,7,12-15]$ and voltammetry $[14,16,17]$ were also applied. Only a single spectrofluorimetric method was reported for the determination of NF using the native fluorescence of 


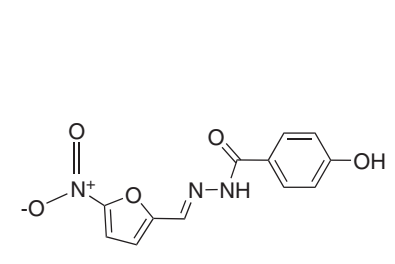

(a)

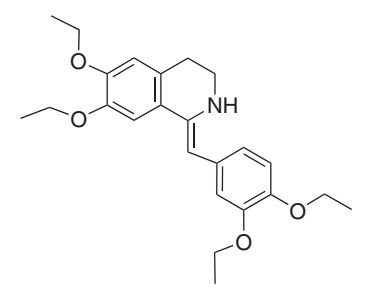

(b)
Scheme 1 Chemical structures of $N F(a)$ and $D V$ (b).

its alkaline degradate [18]. Pharmaceutical dosage form containing a binary mixture of $N F$ and drotaverine $(D V$, Scheme 1b), is well established as an intestinal antiseptic antispasmodic formulation. Spectrophotometric, TLC and HPLC [19-21] methods were developed for the simultaneous determination of $N F$ and $D V$ in capsules.

Two drawbacks were found in the reported spectrofluorimetric method. First, the method could not be applied for the determination of $N F$ in presence of $D V$, since the alkaline conditions required would lead to degradation of $D V$ [22]. Second, the optimization of the procedure conditions was performed one variable at a time (OVAT approach) which does not guarantee at all that the real optimum will be reached. This approach would be valid only if the variables to be optimized were totally independent from each other [23]. In addition, OVAT approach requires a vast number of experiments to establish optimum levels and therefore, is time and budget consuming. These limitations can be eliminated by using experimental design (DOE) which is considered a more efficient systematic optimization technique. It has attracted attention as a multivariate optimizing approach as it takes into account the interaction among relevant factors affecting any chemical reaction. Moreover, this approach offers distinct advantages over OVAT approach, such as, the use of minimum number of experiments and feasibility of generating data that may be analyzed statistically to provide valuable information on the interactions among experimental parameters [24,25].

Based on the aforementioned observations, the main objective of this work was to develop and optimize a new spectrofluorimetric method for the determination of $N F$, based on the formation of a highly fluorescent coumarin via Von Pechmann - Duisberg condensation reaction. The optimum spectrofluorimetric conditions were estimated by a face centered composite (FCC) design using both mathematical and graphical global optimization approaches. The coumarin product was isolated and its structure was identified by IR, ${ }^{1} \mathrm{H}-\mathrm{NMR}$ and mass spectroscopy. The proposed method was tested for linearity, accuracy, intraday and interday precision. Finally, the selectivity of the suggested method was checked by the analysis of NF in presence of the comixed drug $D V$.

\section{Experimental}

Instrumentation

All fluorescence measurements were carried out using a Shimadzu RF - 1501 Spectrofluorophotometer (Shimadzu Kyoto, Japan), with excitation and emission band pass of $5 \mathrm{~nm}$ using $1 \mathrm{~cm}$ quartz cell. Sonication was performed on ultrasonic processor; Soniclean 120T, 220/240v, 50/ $60 \mathrm{~Hz}, 60 \mathrm{~W}$ (Thebarton SA, Australia). Experimental matrices, three dimensional (3D) surface plots and contour curves were generated using Minitab (Version 15) statistical software, State College, Pennsylvania, USA. IR and MS analysis were performed at micro-analytical center, Faculty of Science, Cairo University. IR spectra were recorded using potassium bromide discs on Shimadzu IR-435 spectrometer (Shimadzu, Kyoto, Japan). Mass spectra were recorded on a Hewlett Packard 5988A GC/MS system (70ev) spectrometer (USA). ${ }^{1} \mathrm{H}-\mathrm{NMR}$ spectra were performed at national research center, on Jeol NMR Varian Gemini 500 MHZ spectrometer (Jeol, Tokyo, Japan, Varian, PaloAito, CA, USA).

\section{Materials and reagents}

All chemicals and solvents were of analytical reagent grade. NF pure sample was kindly supplied by Amoun Pharmaceutical Co., El-Obour City, Egypt. Its purity was checked according to spectrophotometric method [19] and was found to be $99.28 \pm 0.745$. Pharmaceutical dosage form containing $N F$ was purchased from the local market. Antinal ${ }^{\circledR}$ capsules (Batch No. 112463) were labeled to contain $200 \mathrm{mg} \mathrm{NF} /$ capsule and drotazide ${ }^{\circledR}$ capsules (Batch No. 012034) were labeled to contain 200 $\mathrm{mg} N F$ and $40 \mathrm{mg} D V /$ capsule. The two pharmaceutical preparations were manufactured by Amoun Pharmaceutical Co., El-Obour City, Egypt. Ethyl acetoacetate (Merck, Germany), labeled to be $98 \%$, was used as freshly prepared $2 \%(\mathrm{v} / \mathrm{v})$ solution in absolute ethanol (Sigma - Aldrich, Germany) and the solutions were discarded regularly every day. Sulfuric acid (Fischer, UK), labeled to be $>95 \% \mathrm{v} / \mathrm{v}$, was used all over the work. Methanol (Riedel - de Haën, Germany) was HPLC grade. Methylene chloride (El-Nasr Pharmaceutical Chemicals, Egypt) was of analytical reagent grade.

\section{Preparation of the standard solutions}

Stock solution $N F$ stock solution was prepared by accurately weighing $10 \mathrm{mg}$ of $N F$ and dissolving in $20 \mathrm{ml}$ absolute ethanol with the aid of sonication for $15 \mathrm{mi}$ nutes in a $100 \mathrm{ml}$ volumetric flask. The volume was completed to the mark with the same solvent to give a final concentration of $100 \mu \mathrm{g} \mathrm{ml}^{-1}$ of $N F$. The solution 
was wrapped in aluminum foil [26] and was stable for at least 7 days if kept in the refrigerator.

Working standard solution A solution of final concentration of $1 \mu \mathrm{g} \mathrm{ml}^{-1}$ was prepared by diluting $1 \mathrm{ml}$ of the standard stock solution to $100 \mathrm{ml}$ using absolute ethanol.

\section{Experimental design for spectrofluorimetric method optimization}

To optimize the critical factors affecting the reaction and explore their effects on the response, a three-level FCC design was applied. Two experimental matrices, each of 11 experiments, were designed, then experimentally performed and the corresponding fluorescence intensities were measured. The factors chosen were volume of ethyl acetoacetate $(E A A)$, volume of sulfuric acid, temperature and heating time. Each factor was tried at three levels. Experimental matrix which contains the coded levels and experimental plan which reports their real values are revealed in Table 1.

The FCC design supports the building of a polynomial equation which takes into account the individual, interactive (usually the interaction among more than two terms are not taken into account) and quadratic terms according to the following mathematical second-order model $[27,28]$ :

$$
Y=b_{0}+b_{1} X_{1}+b_{2} X_{2}+b_{12} X_{1} X_{2}+b_{11} X_{1}^{2}+b_{22} X_{2}^{2}
$$

Where $\mathrm{Y}$ is the response, $\mathrm{b}_{0}$ is the arithmetic mean response, $b_{1}$ and $b_{2}$ are the regression coefficients of the factors $X_{1}$ and $X_{2}$, respectively and $b_{12}, b_{11}$ and $b_{22}$ are interaction and square regression coefficients terms, respectively. The terms $b_{1} X_{1}$ and $b_{2} X_{2}$ are the individual effects of each factor, $b_{12} X_{1} X_{2}$ indicates the interaction among the factors and the terms $\mathrm{b}_{11} \mathrm{X}_{1}^{2}, \mathrm{~b}_{22} \mathrm{X}_{2}^{2}$ takes into account a possible non-linear (quadratic) effects of some factors.

Response surface and contour plots were constructed to evaluate the optimum conditions for the response. Plots of residuals and a lack of fit test with the analysis of variance (ANOVA) model were conducted to assure the adequacy of the model.

\section{Construction of calibration graph}

To a set of $10 \mathrm{ml}$ volumetric flasks, different aliquots equivalent to (200 - $4000 \mathrm{ng})$ from the working standard solution of the drug were quantitatively transferred and then were evaporated to dryness on a boiling water bath. The flasks were then left to cool to room temperature. $E A A$ solution $(0.1 \mathrm{ml}, 2 \% \mathrm{v} / \mathrm{v})$ was added to each flask followed by cautious dropwise addition of sulfuric acid $(2.5 \mathrm{ml})$. The flasks were heated in a water bath adjusted at $40^{\circ} \mathrm{C}$ for 20 minutes, left to cool to room temperature and then the volume was completed to the mark with methanol. The fluorescence intensities of the resulting solutions were measured at $390 \mathrm{~nm}$ after excitation at $340 \mathrm{~nm}$. The calibration graph was obtained by plotting the fluorescence intensities versus the corresponding concentrations and the regression equation was computed.

\section{Analysis of pharmaceutical dosage form}

Accurate weights of the mixed contents of either 20 Antinal $^{\circledR}$ capsules or drotazide ${ }^{\circledR}$ capsules equivalent to $10 \mathrm{mg}$ of $N F$ were transferred quantitatively to two 100 $\mathrm{ml}$ volumetric flasks and about $50 \mathrm{ml}$ of absolute ethanol were added to each flask. The content of each flask was sonicated for 15 minutes, completed to volume with the same solvent, filtered and then, the first portion of the

Table 1 Experimental matrix and experimental plan of the face centered composite design

\begin{tabular}{|c|c|c|c|c|c|c|c|c|}
\hline \multirow{2}{*}{$\begin{array}{l}\text { Number of } \\
\text { experiments }\end{array}$} & \multicolumn{8}{|c|}{ Experimental variables } \\
\hline & $\overline{X_{1}}$ & $\mathrm{X}_{2}$ & $X_{3}$ & $\mathrm{X}_{4}$ & $\begin{array}{c}\text { Volume of } \\
\text { EAA (ml) }\end{array}$ & $\begin{array}{l}\text { Volume of } \\
\mathrm{H}_{2} \mathrm{SO}_{4}(\mathrm{ml})\end{array}$ & Temperature $\left({ }^{\circ} \mathrm{C}\right)$ & $\begin{array}{c}\text { Heating } \\
\text { time }(\mathrm{min})\end{array}$ \\
\hline 1 & 1 & 0 & -1 & -1 & 0.3 & 1.5 & 25 & 10 \\
\hline 2 & 0 & 1 & 1 & 1 & 0.2 & 2.5 & 55 & 30 \\
\hline 3 & 1 & -1 & -1 & 1 & 0.3 & 0.5 & 25 & 30 \\
\hline 4 & 0 & 0 & 0 & 0 & 0.2 & 1.5 & 40 & 20 \\
\hline 5 & -1 & 1 & 0 & -1 & 0.1 & 2.5 & 40 & 10 \\
\hline 6 & -1 & 0 & -1 & 0 & 0.1 & 1.5 & 25 & 20 \\
\hline 7 & 0 & 0 & 0 & 0 & 0.2 & 1.5 & 40 & 20 \\
\hline 8 & 0 & -1 & 1 & 0 & 0.2 & 0.5 & 55 & 20 \\
\hline 9 & 1 & 1 & 1 & -1 & 0.3 & 2.5 & 55 & 10 \\
\hline 10 & -1 & -1 & 0 & 1 & 0.1 & 0.5 & 40 & 30 \\
\hline 11 & 0 & 0 & 0 & 0 & 0.2 & 1.5 & 40 & 20 \\
\hline
\end{tabular}


filtrate was rejected. Further dilution was done in order to obtain a working standard solution of $1 \mu \mathrm{g} \mathrm{m} l^{-1}$ using absolute ethanol. Different aliquots of the working standard solution were analyzed using the procedure mentioned under "Construction of calibration graph".

\section{Method validation}

The newly developed method was validated in terms of linearity, accuracy, precision, selectivity, limit of detection (LOD) and limit of quantification (LOQ), according to the International Conference on Harmonization (ICH) Q2 (R1) guidelines [29].

\section{Linearity and range}

The linearity of the method was checked by analyzing five different solutions of $N F$ over the concentration range $20-400 \mathrm{ng} \mathrm{ml}^{-1}$. Each solution was prepared and analyzed in triplicate. Calibration curve was constructed as fluorescence intensity versus the concentration of the drug and the linear relationship was determined.

\section{Accuracy}

The accuracy of the method was tested by analyzing solutions of the drug in triplicate at concentrations 50, 150,250 and $350 \mathrm{ng} \mathrm{ml}^{-1}$ by using the previously mentioned experimental conditions and comparing measured and calculated values. Percentage recoveries, the mean recovery and the standard deviation (SD) were calculated. In addition, accuracy and validity of the method was determined by standard addition technique in which the recoveries of known amounts of NF, added to the sample solution of known concentration, were calculated.

\section{Precision}

The repeatability (intraday precision) was determined by replicate analysis $(\mathrm{n}=3)$ of standard solutions at low and high concentration levels (100 and $350 \mathrm{ng} \mathrm{ml}^{-1}$ ). The intermediate precision (interday precision) was conducted by repeating the analysis over a period of three consecutive working days. The overall precision of the method was expressed as percentage relative standard deviations (\% RSD).

\section{Selectivity}

Selectivity was investigated by analyzing $N F$ in pharmaceutical dosage form containing binary mixture of $N F$ and $D V$. Percentage recoveries of $N F$ were calculated.

\section{Limit of detection and limit of quantification}

LOD and LOQ of the developed method for the analysis of $N F$ were established according to (ICH) Q2 (R1) guidelines, based on the standard deviation of the response and the slope, using the following equation:

$$
\mathrm{LOD}=3.3 \times \mathrm{SD} / \text { slope } \cdots \cdots \cdot \mathrm{LOQ}=10 \times \mathrm{SD} / \text { slope }
$$

\section{Results and discussion}

Compared to absorption spectroscopic methods, the most attractive features of spectrofluorimetric analysis are high sensitivity and high selectivity. Its sensitivity is one to three orders of magnitude better than absorption spectroscopy while its greater selectivity is based on the fact that fewer substances fluoresce than absorb radiation $[30,31]$. Another advantage is the large linear concentration range of spectrofluorimetric methods which is greater than those encountered in absorption spectroscopy [32].

\section{Optimization of reaction conditions}

OVAT approach, which was traditionally employed for method development, generally requires a large number of experimental runs. In addition, it does not include interaction term and thus it does not depict the collective effects of various factors on the response [33]. To overcome this problem, the optimal reaction conditions were defined by applying DOE, in which factors are varied together. It is a statistical technique for quickly optimizing performance of systems, with two general issues, first, designing an optimal experiment and second, analyzing its results $[24,28]$.

\section{Preliminary study and factor selection}

Some studies were carried out prior to the optimization by DOE. Excitation and emission wavelengths were optimized by searching the maximum fluorescence intensity by means of the recorded spectra. The excitation and emission optimal wavelengths were 340 $\mathrm{nm}$ and $390 \mathrm{~nm}$, respectively. Several solvents were tested for the fluorescent measurements (methanol, ethanol, acetonitrile and water) and maximum fluorescence intensity was obtained with methanol. Preliminary investigations reveal that four factors could be relevant and affect the reaction. Volumes of EAA $\left(\mathrm{X}_{1}\right)$, volume of sulfuric acid $\left(\mathrm{X}_{2}\right)$, temperature $\left(\mathrm{X}_{3}\right)$ and heating time $\left(\mathrm{X}_{4}\right)$ were considered the critical factors to be studied in order to establish an optimum fluorescence.

\section{Face centered composite design}

Factorial design, in which factors are set at two levels, assumes that the effect of factors on the response is linear (first-order factor effects). Since the yield of the chemical reaction is a function of time and temperature which are usually related in a curvilinear fashion to the resultant yield, center-point (the mean 
value of a factor) should be added in the center of the design, resulting in star design. The face centered composite design (FCC) is a special case of central composite design and is composed by a factorial design and a star design. It was utilized to evaluate the main, interaction and quadratic effects of the studied factors on the response [23,28].

Experimental matrix of FCC was built using each two factors at three levels. The number of experimental runs was $2^{\mathrm{K}}+2 \mathrm{~K}+1$, where $\mathrm{K}$ was the number of factors. The first $2^{\mathrm{K}}$ runs were the same as factorial design, the next $2 \mathrm{~K}$ axial experiments were symmetrically spaced at \pm 1 along each variable axis and at least one central point. Two to five center repetitions were generally carried out in order to know the experimental variance and to test the predictive validity of the model [34]. Therefore, a two- factor FCC design required 11 runs (with two center repetitions) while a four-factor FCC design required 27 runs. For this reason, in order to decrease number of experiments, the four critical factors of the reaction were divided into two separate models. Each two factors were chosen based on the interaction plots, Figure 1, where the relative slopes of the lines depicted the presence of interaction between $\left(\mathrm{X}_{1}, \mathrm{X}_{2}\right)$ and $\left(\mathrm{X}_{3}\right.$, $\mathrm{X}_{4}$ ). The factors were tried at three levels and levels were coded for simplification, -1 for the minimum value, +1 for the maximum value and 0 for the central one. Accordingly, two experimental matrices, each of 11 experiments, were designed and all experiments were performed in randomized order to minimize any bias on the response due to uncontrolled factors [24]. Experimental matrix and plan were reported in Table 1.

The coefficients of the second-order polynomial model were computed and the following equation models were obtained:

$$
\begin{aligned}
Y= & 159.48-75.37 X_{1} \\
& +145.62 X_{2}-88.28 X_{1} X_{2}+42.99 X_{1}^{2} \\
& +132.56 X_{2}^{2} \\
Y= & 701.72+193.67 X_{3} \\
& +47.41 X_{4}-34.58 X_{3} X_{4}-203.80 X_{3}^{2}-2.75 X_{4}^{2}
\end{aligned}
$$

Where $\mathrm{Y}$ is the fluorescence intensity, $\mathrm{X}_{1}, \mathrm{X}_{2}, \mathrm{X}_{3}$, and $\mathrm{X}_{4}$ are volume of EAA, volume of sulfuric acid, temperature and heating time, respectively. By simply replacing $\mathrm{X}_{1}, \mathrm{X}_{2}, \mathrm{X}_{3}$, and $\mathrm{X}_{4}$, it will be possible to predict the response for any possible setting, even for those experiments that have not been actually performed.

Equations $(1,2)$ reveal that the fluorescence intensity is inversely related to the volume of EAA. While the increase in volume of sulfuric acid and temperature significantly increases the fluorescence intensity. However, the highly significant quadratic terms ( $X_{2}^{2}$ and $\left.X_{3}^{2}\right)$

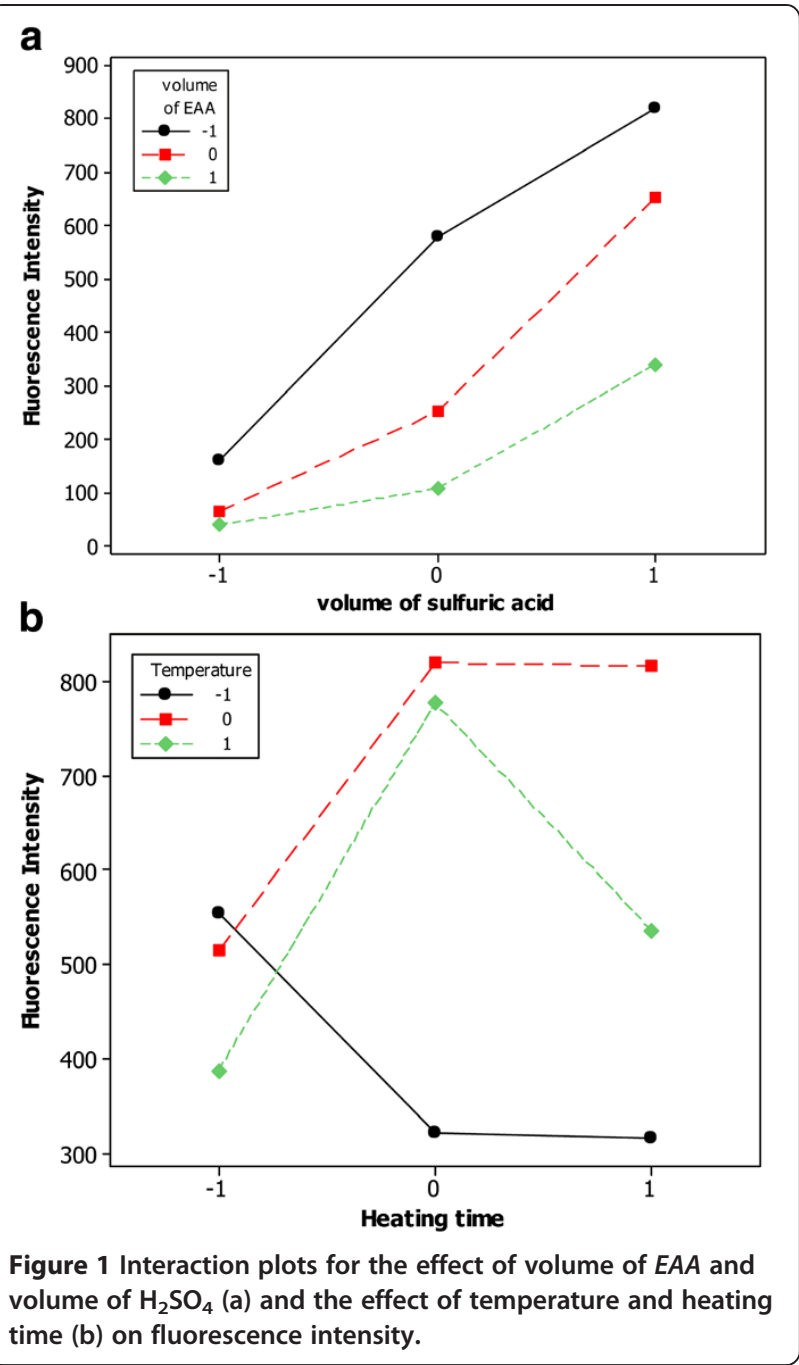

indicate a possible curvature and non-linear correlation between the factor and the output of the equation. The individual effects of temperature and heating time are positive and their quadratic effects are negative thus indicating that the fluorescence intensity increases with increasing of the factor up to a critical threshold after which a further increase results in a decrease of the response ( 0 level of $X_{3}$ and $X_{4}$ were chosen). In addition, the significant interaction between volumes of EAA and sulfuric acid and that of temperature and heating time decreases the fluorescence. Another interesting idea can be inferred from the interactive terms, where the negative sign suggests that each two factors act in a negative way each other, i.e. to increase the response, volume of EAA is maintained at low level while increasing that of sulfuric acid. Regression Table 2 reveals the values of regression coefficients and their associated $p$-values, which are used to determine which of the effects in the model are statistically significant. It was observed that all the four factors and $X_{1} X_{2}$ interaction significantly affect the 
Table 2 Estimated regression coefficients and associated probability values ( $p$-value) for fluorescence intensity

\begin{tabular}{|c|c|c|c|c|c|}
\hline \multirow{2}{*}{$\begin{array}{l}\text { Equation (1) } \\
\text { Term }\end{array}$} & \multirow[b]{2}{*}{ Coefficients } & \multirow[b]{2}{*}{$p$} & \multicolumn{3}{|l|}{ Equation (2) } \\
\hline & & & Term & Coefficients & $p$ \\
\hline Constant & 159.48 & 0.001 & Constant & 701.72 & 0.000 \\
\hline Volume of EAA & -75.37 & 0.023 & Temperature & 193.67 & 0.000 \\
\hline Volume of sulfuric acid & 145.62 & 0.001 & Heating time & 47.41 & 0.035 \\
\hline Volume of EAA * Volume of EAA & 42.99 & 0.299 & Temperature ${ }^{*}$ Temperature & -203.80 & 0.000 \\
\hline Volume of sulfuric acid * Volume of sulfuric acid & 132.56 & 0.011 & Heating time ${ }^{*}$ Heating time & -2.75 & 0.921 \\
\hline Volume of EAA* Volume of sulfuric acid & -88.28 & 0.028 & Temperature ${ }^{*}$ Heating time & -34.58 & 0.165 \\
\hline
\end{tabular}

fluorescence intensity $(p<0.05)$, i.e. the fluorescence intensity differs depending on the four factors and the effect of volume of EAA on the response depends on the volume of sulfuric acid. Significant quadratic effect $X_{3}^{2}$ assures that the relationship between volume of sulfuric acid and fluorescence intensity followed a curved line rather than a straight line. However, $\mathrm{X}_{3} \mathrm{X}_{4}$ interaction and the quadratic models $X_{1}^{2}$ and $X_{4}^{2}$ did not have a significant effect on the response $(p>0.05)$.

Pareto charts, Figure 2, reveal the factors that were statistically significant $(p<0.05)$. It contains a bar for each factor whose length is proportional to its corresponding effect on the reaction [35]. Each factor is significant as individual, moreover, the statistical analysis highlights a significant effect of the interaction of volume of EAA and that of sulfuric acid.

\section{Graphical evaluation of FCC design}

Polynomial equations were graphically represented by a response surface plot which is a $3 \mathrm{D}$ plot reporting the interaction of two factors and their effect on the equation output, the target optimum is the top of the mountain. A modification of the surface response plot is the contour plot, reporting the interactions in a twodimensional (2D) figure, the target optimum is close to the centre of the contours [24]. Response surface and contour plots, related to each model, were analyzed to visualize the parameters and their interactions on the response. Figure 3 confirm the results predicted from the mathematical equations, optimal conditions for the suggested procedure were also deduced. Surface plot, Figure $4 \mathrm{a}_{1}$, reveals that the highest fluorescence intensity was obtained when the volume of EAA was $0.1 \mathrm{ml}$ and that of sulfuric was $2.5 \mathrm{ml}$. In addition, Figure $4 \mathrm{a}_{2}$ reveals a maximal response value which corresponds to $40^{\circ} \mathrm{C}$ temperature and $20 \mathrm{~min}$ heating time. Contour plots, Figure $4 b_{1}$ and $4 b_{2}$, show curvature indicating the non-linear effects of these factors on fluorescence intensity. Contour plots assist the prediction of response at any area of the experimental domain [24].

\section{Residual analysis}

Residuals are the deviations of the observed values of the response from the predicted values, given the current model. Examination of residuals assists in checking model adequacy [28]. Residual plots are used to evaluate the data for nonnormality, nonrandom variation, nonconstant variance and outliers. Normal plot of the residuals reveals that the residuals follow a straight line, which indicates that the errors are normally distributed, Figure 4. Histogram of the residuals is bell-shaped indicating the absence of skewness and outliers. Based on residuals versus fits plot, the residuals appear to be randomly scattered about zero,

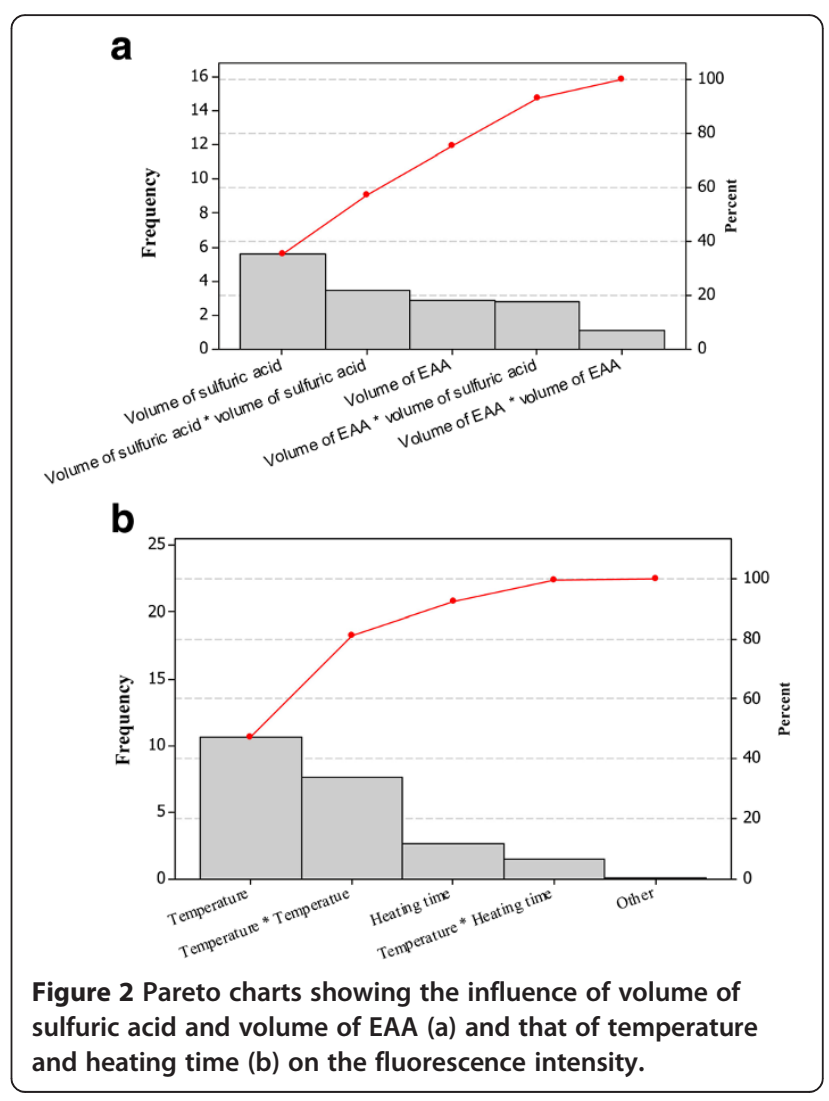



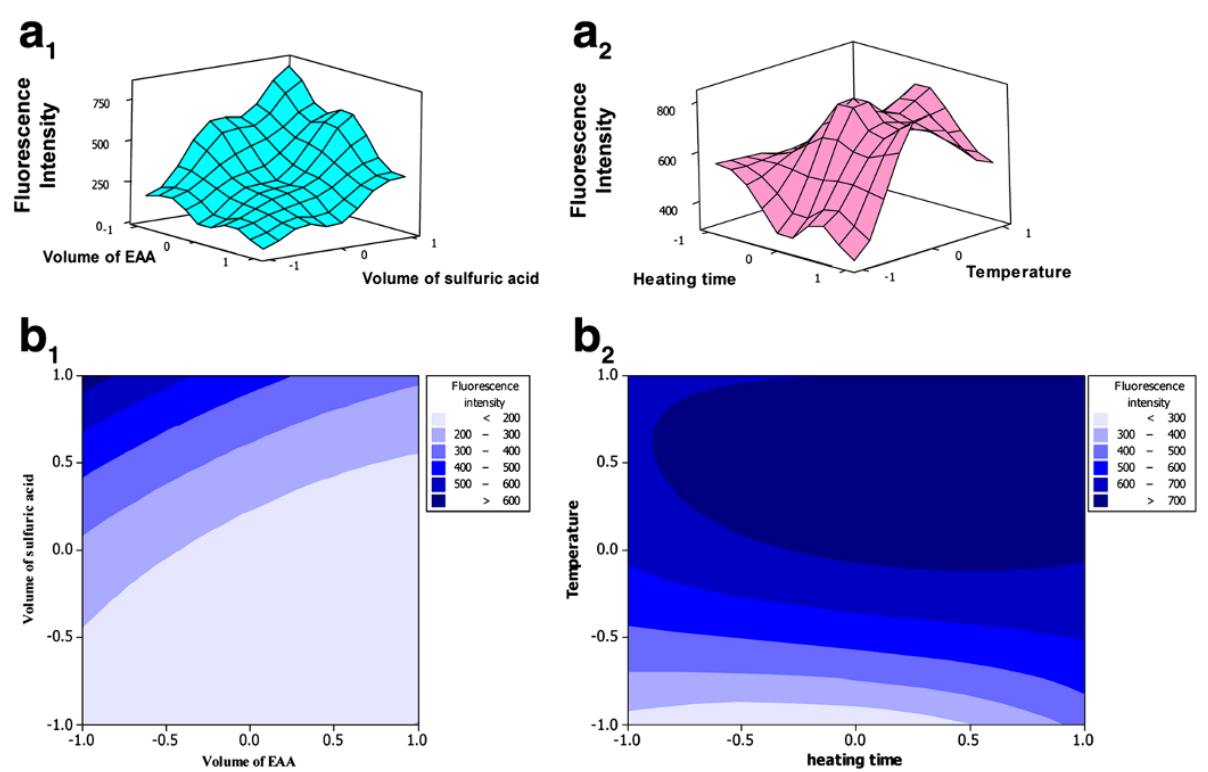

Figure 3 Response surface plots (a) and contour plots (b) showing the effect of volume of EAA, volume of sulfuric acid $\left(a_{1}, b_{1}\right)$ and temperature and heating time $\left(a_{2}, b_{2}\right)$ on fluorescence intensity.

therefore, there is no evidence of nonconstant variance. The residuals in the residuals versus order plot fluctuate in a random pattern around the center line and hence no evidence exists that the error terms are correlated with one another [25], Figure 4. Therefore, residual analysis supports the fact that the model fits the data adequately.

\section{Statistical analysis of the model}

Along with the polynomial equation, the main outputs of a FCC design are some statistical parameters that measure the goodness of fitting of the proposed equation. The model was validated by ANOVA, Table 3. In ANOVA analysis, a significant model and a non significant lack of fit are desired as a model that fits the data is essential for optimization studies [25]. The regression models are significant $(p=0.002,0.000)$, that is, at least one of the terms in the regression equation makes a significant impact on the mean response. The $p$-value for the squared effects is less than 0.05 . Therefore, there is a significant quadratic effect, that is, the relationship between $X_{2}^{2}$ and $X_{3}^{2}$ and yield does not follow a straight line but rather a curved line. The $p$-value of 0.028 for the volume of EAA by volume of sulfuric acid interaction implies a significant interaction effect, that is, the effect of volume of EAA on reaction yield depends on volume of sulfuric acid. On the other hand, temperature and heating time interaction is non-significant $(p=0.165)$. Although the model exhibits highly significant factor effects, Lack-of-fit is also highly significant. Such a situation often arises if the model fits the data well and if the measurement process is highly precise [27]. Therefore, the models that have been developed can be used to predict the fluorescence intensity of $N F$ within the limits of the experiment [25].

\section{Reaction mechanism}

Upon optimization of the factors affecting the fluorescence intensity, the spectrofluorimetric method was applied to the determination of $N F$ in pure form and in capsules. The procedure consists in condensation of the phenolic derivative with $\beta$-ketoester in presence of excess acid as catalyst, leading to the formation of a $\beta$ hydroxyester [36]. By analogy to previous reports, the reaction was proposed to proceed as shown in Scheme 2. $N F$ (bearing a phenolic group) readily coupled with EAA, in presence of sulfuric acid as dehydrating agent, producing a yellow highly fluorescent coumarin compound, which exhibited a fluorescence maximum at $390 \mathrm{~nm}$ when excited at $340 \mathrm{~nm}$, Figure 5. The coumarin derivative was formed immediately and was stable for at least two hours. The Von Pechmann-Duisberg condensation proved to be efficient and simple reaction used to produce fluorescent coumarins. It was found that addition of EAA and sulfuric acid to different aliquots of $N F$ working standard solution in absolute ethanol leads to non reproducible results. It was thought that variation of volume of absolute ethanol from one aliquot to another was the reason for the non reproducibility. Therefore, the aliquots were evaporated to dryness on a boiling water bath and then, cooled before adding EAA and sulfuric acid, thus leading to reproducible results. 

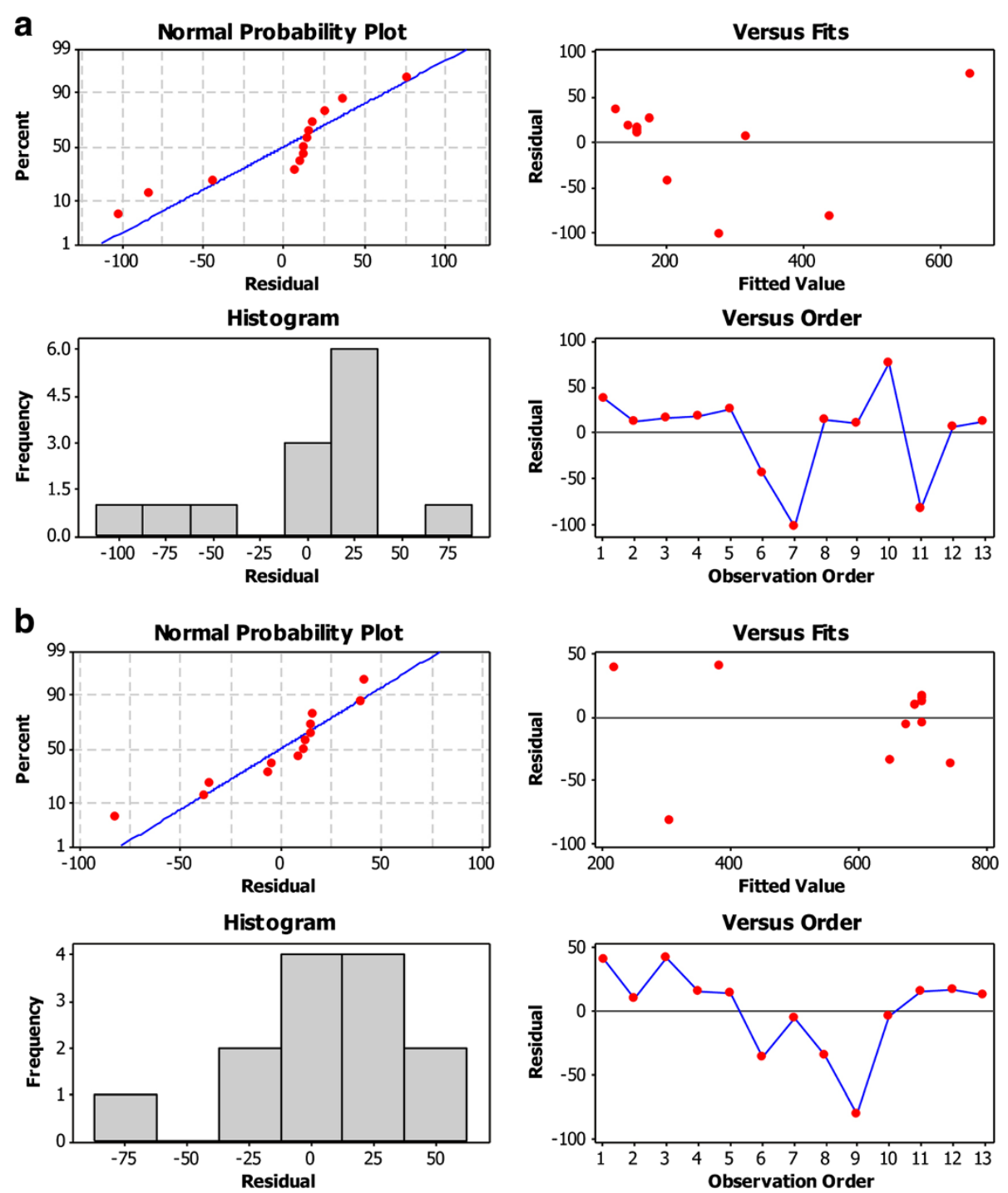

Figure 4 Normal probability plot, histogram, residuals versus fits and residuals versus order for fluorescence intensity, model 1 (a) and model 2 (b).

Isolation and identification of the coumarin product

To $0.5 \mathrm{gm} \mathrm{NF}$, EAA $(3 \mathrm{ml})$ and sulfuric acid $(10 \mathrm{ml})$ were added. The mixture was heated in a water bath at $40^{\circ} \mathrm{C}$ for $20 \mathrm{~min}$. The reaction mixture was cooled, then poured on crushed ice and stirred for 15 minutes. The product was extracted from the reaction mixture twice with methylene chloride $(50 \times 2)$. After extraction, the organic layer was left to evaporate and the obtained concentrated extract was collected. The assignment of the formed coumarin was based on the comparison of the IR and ${ }^{1} \mathrm{H}$ NMR spectral data with those of the intact drug. The IR spectrum of the coumarin product revealed the disappearance of the phenolic band at $3361.32 \mathrm{~cm}^{-1}$ in the IR spectrum of $N F$, meanwhile, the appearance of the lactone $\mathrm{C}=\mathrm{O}$ band at $1729.8 \mathrm{~cm}^{-1}$. The ${ }^{1} \mathrm{H}-\mathrm{NMR}$ spectrum of the coumarin product revealed the
Table 3 Analysis of variance (ANOVA) results for fluorescence intensity

\begin{tabular}{lllll}
\hline Model (1) & & & Model (2) & \\
\cline { 1 - 2 } Source & $\boldsymbol{p}$ & & Source & $\boldsymbol{p}$ \\
\hline Regression & 0.002 & & Regression & 0.000 \\
Linear & 0.001 & & Linear & 0.000 \\
Square & 0.010 & & Square & 0.000 \\
Interaction & 0.028 & & Interaction & 0.165 \\
Residual error & & & Residual error & \\
Lack-of-fit & 0.000 & & Lack-of-fit & 0.000 \\
\hline
\end{tabular}




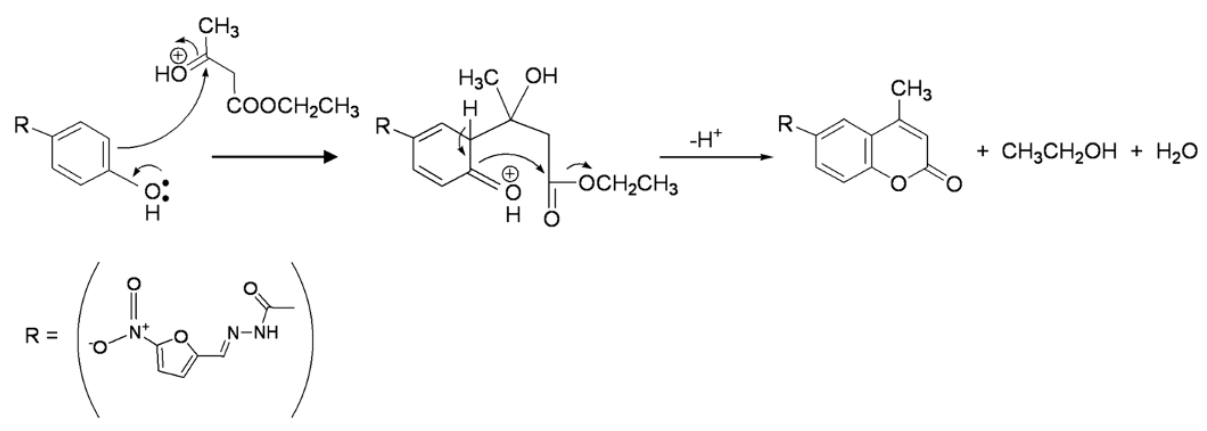

Scheme 2 Suggested pathway for the reaction between NF and $E A A / \mathrm{H}_{2} \mathrm{SO}_{4}$.

appearance of a singlet signal at $\delta 2.1387 \mathrm{ppm}$, integrated for three protons due to $\mathrm{CH}_{3}$ group and a singlet signal at $\delta 6.1112 \mathrm{ppm}$, integrated for one proton due to $\mathrm{CH}$ of the lactone ring. Moreover, the molecular weight of the coumarin product was confirmed by mass spectrum which revealed the molecular ion peak $\left(\mathrm{M}^{+}\right)$at 341 .

\section{Method validation}

The optimized spectrofluorimetric method was validated according to (ICH) Q2 (R1) guidelines [29].

\section{Linearity and range}

Applying the procedure mentioned under construction of a calibration graph, the relationship between NF concentration and fluorescence intensity was found to be linear. The good linear relationship was revealed by the high value of the correlation coefficient. Descriptive statistics of the regression line showed low values of standard error of estimation, standard error of slope $\left(S_{b}\right)$ and that of intercept $\left(S_{a}\right)$ which revealed high accuracy with minimum deviations and low scattering of the calibration points, Table 4 .

\section{Accuracy}

Accuracy of the analytical procedure is the closeness of agreement between a true value and the value obtained.

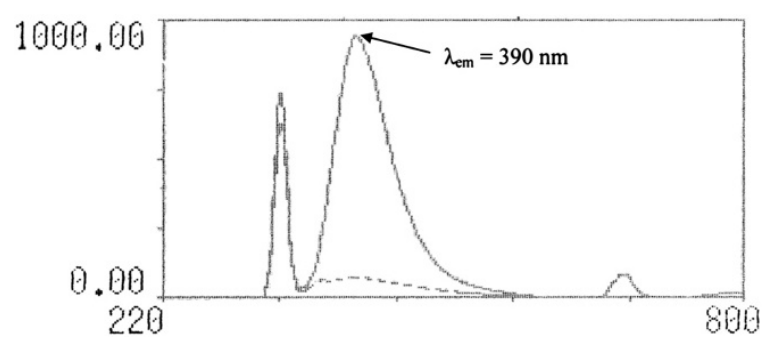

Figure 5 Excitation and emission spectra of the coumarin product produced by reaction between $350 \mathrm{ng} \mathrm{ml}^{-1}$ of $N F$ and $E A A$ in methanol ( $\mathrm{nm}, \lambda_{\mathrm{em}}=390 \mathrm{~nm}$ ).
Table 5 reveals that the SD values for all the samples were less than $1 \%$ suggesting that the method was accurate.

Furthermore, standard addition technique showed satisfactory results as the percentage recoveries achieved ranged between 98.38 and $100.97 \%$ and the corresponding SD were well below 1\%, indicating that the method was accurate and valid, Table 6.

\section{Precision}

Results for the determination of repeatability and intermediate precision are displayed in Table 4. Low values of

Table 4 Assay parameters and method validation obtained by applying spectrofluorimetric method for the determination of $\mathbf{N F}$

\begin{tabular}{ll}
\hline Parameter & NF \\
\hline Excitation wavelength & $340 \mathrm{~nm}$ \\
Emission wavelength & $390 \mathrm{~nm}$ \\
Range of linearity & $20-400 \mathrm{ng} \mathrm{ml}^{-1}$ \\
Regression equation & $\mathrm{y}=1448.447 x+101.590$ \\
Correlation coefficient $(r)$ & 0.9997 \\
$S_{b}$ & 14.185 \\
$S_{a}$ & 3.477 \\
Confidence limit of the slope & $1448.447 \pm 45.137$ \\
Confidence limit of the intercept & $101.590 \pm 11.064$ \\
Standard error of the estimation & 4.310 \\
LOD $^{\text {a }}$ & $0.01 \mathrm{ng} \mathrm{ml}^{-1}$ \\
LOQ $^{\text {a }}$ & $0.03 \mathrm{ng} \mathrm{ml}^{-1}$ \\
Intraday $^{\text {b }}$ & \\
\% RSD & $0.692-0.598$ \\
Interday & \\
\% RSD & $0.688-0.395$
\end{tabular}

${ }^{a}$ Limits of detection and quantification are determined via calculations [29]: $\mathrm{LOD}=3.3 \times \mathrm{SD} /$ slope $\mathrm{LOQ}=10 \times \mathrm{SD} /$ slope, where $\mathrm{SD}$ is standard deviation of response.

${ }^{\mathrm{b}}$ The intraday $(n=3)$, average of two concentrations of $\mathrm{NF}\left(100,350 \mathrm{ng} \mathrm{ml}^{-1}\right)$, repeated three times within the day.

c The interday $(n=3)$, average of two concentrations of NF $\left(100,350 \mathrm{ng} \mathrm{ml}^{-1}\right)$, repeated three times in three successive days. 
Table 5 Application of the proposed spectrofluorimetric method for the determination of $N F$ in pure samples

\begin{tabular}{|c|c|c|}
\hline Claimed taken $\left(\mathrm{ng} \mathrm{ml}^{-1}\right)$ & Claimed found (ng ml${ }^{-1}$ ) & $\%$ Recovery $^{\mathrm{a}}$ \\
\hline 50 & 49.991 & 99.98 \\
\hline 150 & 150.009 & 100.07 \\
\hline 250 & 250.896 & 100.36 \\
\hline 350 & 347.552 & 99.30 \\
\hline Mean & & 99.93 \\
\hline $\pm S D$ & & 0.449 \\
\hline
\end{tabular}

${ }^{a}$ Average of three determinations.

$\%$ RSD confirmed that the suggested method was precise, has good repeatability and hence, was satisfactory for quality control measurements.

\section{Selectivity}

Selectivity is the ability of the analytical method to measure the analyte response in presence of interferences. It was ascertained by applying the method to the pharmaceutical dosage form containing the coformulated drug $D V$. Results in Table 6 reveal that no interference was observed either from $D V$ or from the frequently encountered excipients, indicating that the proposed method was highly selective for the analysis of NF. Moreover, results close to $100 \%$ were obtained for the determination of NF in dosage form, Table 6. These results confirm the selectivity of the method.

\section{Limit of detection and limit of quantification}

The LOD obtained with the developed method was 0.01 $\mathrm{ng} \mathrm{ml}{ }^{-1}$, as shown in Table 4. Therefore, the proposed method was found to be more sensitive than the
Table 7 Statistical analysis of the results obtained by applying the proposed spectrofluorimetric method and the reference method

\begin{tabular}{llll}
\hline NF & Item & Spectrofluorimetry & $\begin{array}{l}\text { Reference } \\
\text { method [19] }\end{array}$ \\
\hline Pure form & Mean & 99.93 & 99.28 \\
& SD & 0.449 & 0.745 \\
& RSD & 0.449 & 0.750 \\
& $n$ & 4 & 5 \\
& Variance & 0.201 & 0.555 \\
& $t$-value & $0.05(2.365)^{*}$ & \\
Antinal ${ }^{\circledR}$ capsules & F-value & $2.761(9.12)^{*}$ & \\
& Mean & 99.93 & 100.49 \\
& SD & 0.524 & 0.955 \\
& RSD & 0.524 & 0.950 \\
& $n$ & 3 & 5 \\
& Variance & 0.275 & 0.912 \\
& $t$-value & $1.07(2.447)^{*}$ & \\
& F-value & $3.316(19.25)^{*}$ &
\end{tabular}

* Figures in parentheses are the corresponding theoretical $t$-and $F$-values at $p=0.05$.

reported spectrofluorimetric one for the determination of $N F$ [18] whose LOD was $0.008 \mu \mathrm{g} \mathrm{ml}^{-1}$.

\section{Statistical analysis}

A reference spectrophotometric method was adopted for the analysis of $N F$ in pure form and in pharmaceutical preparation [19]. Statistical comparison of the results obtained by the proposed and reported methods is shown in Table 7. The calculated $t$ - and $F$ - values are less than the theoretical ones indicating that there

Table 6 Determination of NF in capsules by the proposed spectrofluorimetric method and application of standard addition technique

\begin{tabular}{|c|c|c|c|c|c|c|c|}
\hline \multicolumn{4}{|c|}{ Antinal $^{\circledR}$ capsules } & \multicolumn{4}{|c|}{ Drotazide $^{\circledR}$ capsules } \\
\hline $\begin{array}{l}\text { Claimed } \\
\left(\mathrm{ng} \mathrm{ml} \mathrm{ml}^{-1}\right)\end{array}$ & $\%$ Recovery $^{a}$ & 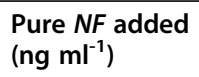 & $\%$ Recovery $^{a}$ & $\begin{array}{l}\text { Claimed } \\
\left(\mathrm{ng} \mathrm{m} \mathbf{~}^{-1}\right)\end{array}$ & $\%$ Recovery $^{a}$ & $\begin{array}{l}\text { Pure } N F \text { added } \\
\left(\text { ng } \mathrm{ml}^{-1}\right)\end{array}$ & \% Recovery ${ }^{a}$ \\
\hline \multirow[t]{3}{*}{100} & 99.70 & 80 & 100.11 & 100 & 99.01 & 80 & 100.97 \\
\hline & & 100 & 100.80 & & & 100 & 98.73 \\
\hline & & 120 & 100.68 & & & 120 & 99.53 \\
\hline \multirow[t]{3}{*}{150} & 100.53 & 120 & 100.11 & 150 & 100.07 & 120 & 100.11 \\
\hline & & 150 & 100.34 & & & 150 & 100.80 \\
\hline & & 170 & 99.90 & & & 170 & 99.50 \\
\hline \multirow[t]{3}{*}{200} & 99.56 & 160 & 98.38 & 200 & 100.25 & 160 & 100.11 \\
\hline & & 180 & 99.72 & & & 180 & 100.87 \\
\hline & & 200 & 99.42 & & & 200 & 99.42 \\
\hline Mean & 99.93 & & 99.94 & & 99.78 & & 100.00 \\
\hline$\pm \mathrm{SD}$ & 0.524 & & 0.730 & & 0.670 & & 0.773 \\
\hline
\end{tabular}

${ }^{a}$ Average of three different determinations. 
is no significant difference between the proposed method and the reported one with respect to accuracy and precision.

\section{Conclusion}

A systematic and practical approach was employed to develop an efficient and selective spectrofluorimetric method to quantify $N F$ in pure and capsule forms. Experimental design was successfully applied to effectively evaluate the main effects of factors that significantly affected the fluorescence intensity and to determine their interactions and quadratic effects with the least number of runs. The application of response surface methodology with face centered composite design to modeling and optimizing the performance of the suggested method proved to be an economic approach for extracting large amount of information while saving time and cost. After optimization, all the performed response surface, contour plots, plots of residuals, lack of fit test and ANOVA results support each other and confirm the adequacy of the model. The method was validated and the obtained results indicate good linearity and reproducibility. The method was further compared with a reported UV method and proved to be more sensitive and selective. The proposed method is accurate, specific, and sensitive so can be applied for the routine analysis of $N F$ in pure form and in pharmaceutical dosage form, either alone or in presence of $D V$.

\section{Abbreviations}

NF: Nifuroxazide; DV: Drotaverine; OVAT: One variable at a time; DOE: Experimental design; FCC design: Face centered composite design; EAA: Ethylacetoacetate; ANOVA: Analysis of variance; ICH: The International Conference on Harmonization; SD: Standard deviation; RSD: Relative standard deviation; LOD: Limit of detection; LOQ: Limit of quantification.

\section{Competing interests}

The authors declare that they have no conflict of interests.

\begin{abstract}
Authors' contributions
AAZ collected the literature review, proposed and explained the experimental design work, revised the manuscript critically, participated in the results, assay validation and discussion. MAM proposed the analytical method, helped in understanding DOE, performed the experimental design work using Minitab software, analyzed the data statistically and prepared the draft version of the manuscript. Both authors conducted the optimization of the assay conditions, carried out the analytical experimental work, read and approved the final manuscript.
\end{abstract}

Received: 19 January 2013 Accepted: 8 May 2013

Published: 23 May 2013

\section{References}

1. O'Neil MJ, Heckelman PE, Koch CB, Roman KJ, Kenny CM, D'Arecca MR: The Merck Index, An Encyclopedia of Chemicals, Drugs and Biologicals. 14th edition. Whitehouse Station, NJ, USA: Merck Research laboratories Division of Merck \& Co., Inc; 2006:1130.

2. Sweetman SC: Martindale, The Complete Drug Reference. 35th edition. London, Chicago: The Pharmaceutical Press; 2007. 274.

3. The British Pharmacopoeia. London, UK: Her Majesty's Stationary Office; 2010:1508.
4. Khier AA, Elhenawee MM, Elmasry MS: Spectrophotometric method for the determination of some drugs using fast red B salt. E-J Chem 2008, 5(S2):1087-1097.

5. Emara KM, Refaat $\Vdash H$, Abdelmageed $\mathrm{OH}$ : HPLC and spectrophotometric determination of nifuroxazide and its pharmaceutical formulations. Egyptian J Pharm Sci 1994, 35(1-6):313-324.

6. Szuminska E, Cisak A: Polarographic and spectrophotometric determination of nifuroxazide in pharmaceuticals. I. Nifuroxazide determination in capsules. Acta Pol Pharm 1988, 45(6):551-558.

7. Szuminska E, Cisak A: Polarographic and spectrophotometric determination of nifuroxazide in pharmaceuticals. II. Determination of nifuroxazide in suspensions. Acta Pol Pharm 1990, 47(1-2):1-2.

8. Toral MI, Paine M, Leyton P, Richter P: Determination of attapulgite and nifuroxazide in pharmaceutical formulations by sequential digital derivative spectrophotometry. J AOAC Int 2004, 87(6):1323-1328.

9. Sobanska AW: Rapid determination of nifuroxazide in tablets by near-infrared spectroscopy. Chemia Analityczna (Warsaw, Poland) 2009, 54(5):1021-1033.

10. Berezkin VG, Onuchak LA, Evtyugina EN: Capillary thin-layer chromatography of antibacterial nitrofuran derivatives. Russ J App/ Chem 2009, 82(2):312-316.

11. Guinebault PR, Broquaire $M$, Braithwaite RA: Determination of nifuroxazide in biological fluids by automated high-performance liquid chromatography with large-volume injection. J Chromatogr 1981, 204:329-333.

12. Squella JA, Lemus I, Lonza G, Nunez-Vergara LJ: Electrochemical study of nifuroxazide and its analytical determination in tablets. Boletin de la Sociedad Chilena de Quimica 1991, 36(2):109-116.

13. Radi A, El-Laban S, Kenawy IMM: Determination of nifuroxazide in capsules by differential pulse polarography. Anal Sci 1998, 14(3):607-608.

14. Buchberger W, Niessner G, Bakry R: Determination of nifuroxazide with polarography and adsorptive stripping voltammetry at mercury and carbon paste electrodes. Fresenius J Anal Chem 1998, 362(2):205-208.

15. Sreedhar NY, Samatha KR, Reddy PRK: Electrochemical reduction behavior and analysis of nifuroxazide in formulations and urine samples. Indian Drugs 1999, 36(8):509-512.

16. Radi A, El Ries MA: Determination of nifuroxazide in human serum by adsorptive stripping voltammetry. Anal Sci 1999, 15(4):385-388.

17. Radi A: Voltammetric study of nifuroxazide at unmodified and Sephadexmodified carbon paste electrodes. Fresenius J Anal Chem 1999, 364(6):590-594.

18. Belal TS: A simple and sensitive spectrofluorimetric method for analysis of some nitrofuran drugs in pharmaceutical preparations. J Fluoresc 2008, 18(5):771-780.

19. Metwally FH, Abdelkawy M, Naguib IA: Determination of nifuroxazide and drotaverine hydrochloride in pharmaceutical preparations by three independent analytical methods. J AOAC Int 2006, 89(1):78-87.

20. Ayad MM, Youssef NF, Abdellatif HE, Soliman SM: A comparative study on various spectrometries with thin layer chromatography for simultaneous analysis of drotaverine and nifuroxazide in capsules. Chem Pharm Bull 2006, 54(6):807-813.

21. Metwally FH: Simultaneous determination of Nifuroxazide and Drotaverine hydrochloride in pharmaceutical preparations by bivariate and multivariate spectral analysis. Spectrochim Acta A Mol Biomol Spectrosc 2008, 69A(2):343-349.

22. Azhlwar S, Ravi TK: Stability indicating HPLC method for simultaneous determination of drotaverine and aceclofenac. Int J Pharm Pharm Sci 2011, 3(1):245-250.

23. Leardi R: Experimental design in chemistry: A tutorial. Anal Chim Acta 2009, 652:161-172.

24. Miller JN, Miller JC: Statistics and Chemometrics for Analytical Chemistry. 6th edition. England: Pearson education Limited; 2010:186-216.

25. Khamanga SM, Walker RB: The use of experimental design in the development of an HPLC-ECD method for the analysis of captopril. Talanta 2011, 83:1037-1049.

26. Boussac N, Galmier MJ, Dauphin G, Madesclaire M, Lartigue C: Nifuroxazide photodecomposition: Identification of the (Z)-isomer by 1H-NMR Study. Mikrochim Acta 2003, 141(3-4):179-181.

27. Deming SN, Morgan SL: Experimental Design: A Chemometric Approach 2nd edition. Amsterdam, London, New York, Tokyo: Elsevier Publishers; 1993:227-274. 151-169.

28. Montgomery DC: Design and Analysis of Experiments. 7th edition. Asia: John Wiley \& Sons, Inc; 2009:207-263. 1-22, 60-114.

29. Q2 (R1) Validation of analytical procedures, Proceedings of the International Conference on Harmonisation (ICH). Geneva: Commission of the European Communities; 2005. 
30. Patnaik P: Dean's Analytical Chemistry Handbook. 2nd edition. New York, London, Toronto: McGraw-Hill; 2004:648.

31. Kellner R, Mermet JM, Otto M, Valcárcel M, Widmer HM: Analytical Chemistry. Weinheim: Wiley-VCH Verlay GmbH \& Co. KGaA; 2004. 746.

32. Skoog DA, West DM, Holler FJ, Crouch SR: Fundamentals of Analytical Chemistry. 8th edition. Australia, United States: Brooks/Cole, a division of Thomson learning, Inc; 2004:825.

33. Cagigal E, González L, Alonso RM, Jiménez RM: Experimental design methodologies to optimize the spectrofluorimetric determination of losartan and valsartan in human urine. Talanta 2001, 54:1121-1133.

34. Srinubabu G, Raju CAl, Sarath N, Kumar PK, Rao JVLNS: Development and validation of a HPLC method for the determination of voriconazole in pharmaceutical formulation using an experimental design. Talanta 2007, 71:1424-1429

35. Awotwe-Otoo D, Agarabi C, Faustino PJ, Habib MJ, Lee S, Khan MA, Shah RB: Application of quality by design elements for the development and optimization of an analytical method for protamine sulfate. I Pharm Biomed Anal 2012, 62:61-67.

36. Belal F, Al-Shaboury S, Al-Tamrah AS: Spectrophotometric determination of labetolol in pharmaceutical preparations and spiked human urine through the formation of coumarin derivative. J Pharm Biomed Anal 2002 30:1191-1196.

doi:10.1186/1752-153X-7-90

Cite this article as: El-Zaher and Mahrouse: A validated

spectrofluorimetric method for the determination of nifuroxazide

through coumarin formation using experimental design. Chemistry

Central Journal 2013 7:90.

\section{Publish with ChemistryCentral and every scientist can read your work free of charge \\ "Open access provides opportunities to our colleagues in other parts of the globe, by allowing anyone to view the content free of charge." \\ W. Jeffery Hurst, The Hershey Company. \\ - available free of charge to the entire scientific community \\ - peer reviewed and published immediately upon acceptance \\ - cited in PubMed and archived on PubMed Central \\ - yours - you keep the copyright \\ Submit your manuscript here: \\ http://www.chemistrycentral.com/manuscript/<smiles>c1ccccc1</smiles> \\ Chemistry Central}

